核融合研究第 14 巻第 2 号 1965 年 2 月

A. Synthesized Plasma

奥田莘美山本蜸三

Takayoshi Okuda and Kerizo Yamamoto

Department of Electronics, Nagoya University

(Received 25th December, 1964)

\title{
Abstract
}

A new method of generating synthesized plasma is proposed. The plasma is produced by mixing electron and ion beams, each of which is separately formed before entering a plasma forming space. This method has an advantage that the mean energy, density and degree of neutrality of charge are controllable.

In this paper, we shall give a brief description of the synthesized plasma, which is mainly aimed at the investigation of various electrostatic instabilities and the thermalization processes.

I. Introduction

The most commonly used method of generating a laboratory plasma is by means of electrical discharge.

Takayoshi Okuda and Kenzo Yamamoto Department of Electronics, Nagoya University 


$$
\text { Okuda . Yamamo to }
$$

The disadvantage of such plasmas is that the plasma parameters such as the mean energy and density are not controllable, in other words, the discharge plasma is more or less a ready-made plasma, in the sense that the energy and density are fixed at certain values depending on the existing loss processes and also the charge neutrality holds automatically.

Furthermore, the discharge plasmas are characterized by low ionization degree, instability and oscillation. Most of the experimentaI works on plasma physics have been carried out in various discharges and the results have been interpreted on the basis of neutral plasma, except for the case of electrostatic oscillation where a small deviation from the neutrality is concerned. If a synthesized plasma in which the plasma parameters are controlled at will is realized, it will allow us to explore new properties of plasma. The plasma oscillation including the two beam instability, the relaxation of energy distribution or thermalization and the propagation of the electromagnetic wave and so on; must also be reexamined by use of the synthesized plasma.

Recently, a method of generating high ionized plasma 


\section{A Synthesized Plasma}

by means of thermionic electron emission combined with surface ionization has been developed, (3) but this type of plasma does not satisfy all of the above requirements. For instance, the energies of the electron and ion are fixed at the values determined by the cathode temperature.

The present paper describes a proposed means of producing the synthesized plasma and a predicted property of the plasma.

II. Plasma Generation

The principle underlying our plasma synthesis is that the ion and electron beams produced in separate chambers are injected into a plasma forming space. The direction of the injection of one beam is taken either parallel or antiparallel to the other.

There is no problem as Iong as the design of the electron gun is concerned. However, the ion source is composed of an arc discharge and an exit aperture which is necessity small in size to obtain a large pressure difference between inside and outside of the source. For this reason, a limitation on the configulation of the system of beams is imposed such a way that the ion beam is annular and encloses the electron 
Okuda - Yamamoto

beam, as shown schematically in fig.l.

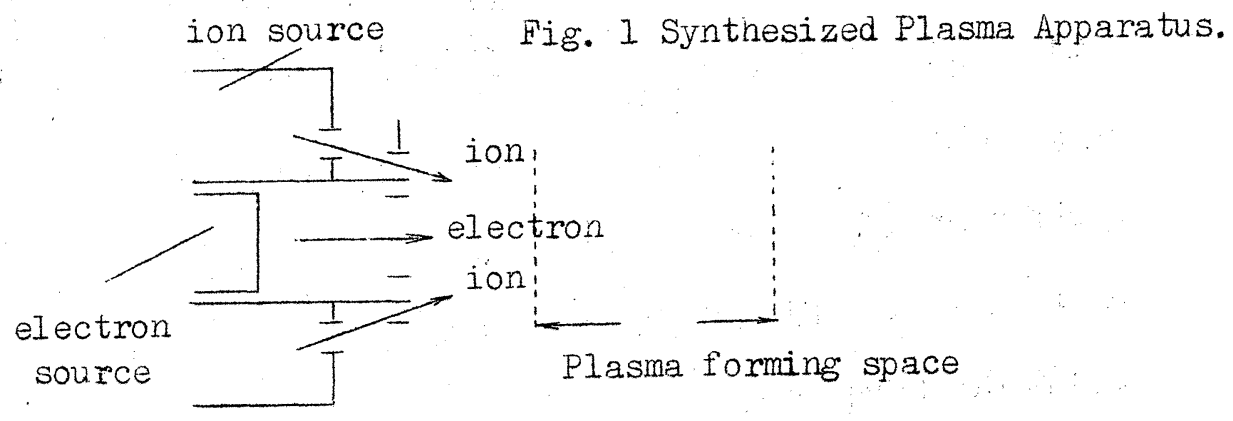

(a) Parallel

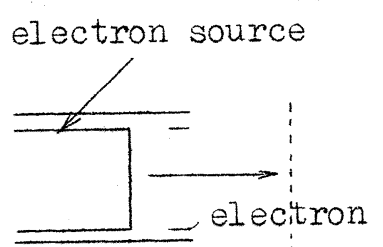

plasma forning

space

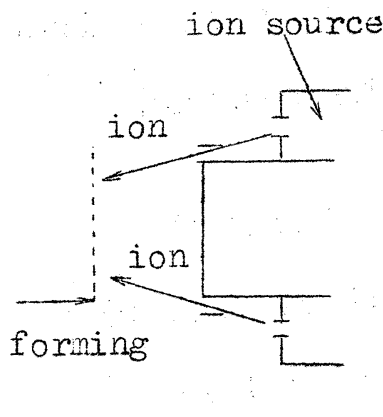

(b) antiparallel

Vanishing electric field or a constant velocity of the charged particle in the plasma forming space is attainable if the charge neutrality holds and the losses in energy anc density are not present. The energy and density are controlled by adjusting the accerelating voltage and beam current, respectively. The relaxation of energy to an equilibrium distribution or thermalization is mainly due to the Coulomb interaction between the charged particles if the residual gas is completely evacuated. 


\section{A Synthesized Plasma}

The principal difference from the ordinary discharge plasma is that the ratio of the directed energy to the thermal energy as well as that of the electron temperatur are arbitraryily selected in the synthesized plasma. The condition that the directed energy is superior to the thermal energy is realized if the secondary electron is produced by ionizing collision with the residual gas atom if any, while the opposite condition, especially an extreme condition of vanishing directed energy is attained with complete thermalization of the injected charged particles.

The usefulness of the synthesized plasma is quite evident. We list below some of interesting subjects which will be investigated with it.

(a) Electrostatic oscillation including two beam instability and beam-plasma interaction.

(b) Relaxation of energy or thermalization of the electron and"ion.

(c) Effect of deviation from the complete neutrality on various properties of plasma.

(d) Space charge neutralization.

III. Property of Synthesized Plasma

In this paragragh, as one of the predicted feature 
Okuda. Yamamo to

of the synthesized plasma the response to a small amplitude a.c. electric field will be discussed. The solution to this problem is usually described in terms of the impedance defined by the ratio of the applied a.c. voltage to the a.c. current flowing in the plasma. For simplicity, we consider a one-dimensional system but contained in a region bounded by two grids. This arrangement is indicated schematically in fig. 2 .

Fig. 2. Illustration of Synthesized "Plesma.

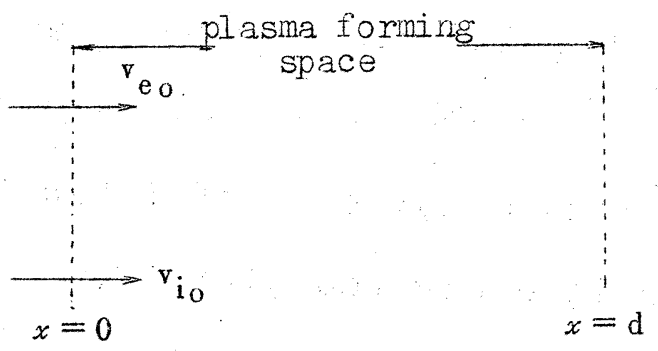

The electron and ion beams are injected into a plasma forming space formed between two grids, with velocities $v_{\text {eo }}$ and $\mathrm{v}_{\mathrm{i}_{0}}$, respectivaly. The plasma thus formed is supposed to be homegeneous.

In the present analysis, we ignore the correlation between electrons and ions via space charge field and collision. With additional assumption that the electron and ion temperatures are held constant when a small amplitude a.c. voltage is applied, the basic 
equations in the macroscopic approach are given as

$$
\begin{aligned}
& \frac{\partial \mathrm{n}_{\mathrm{e}}}{\partial \mathrm{t}}+\frac{\partial}{\partial x}\left(\mathrm{n}_{\mathrm{e}} \mathrm{v}_{\mathrm{e}}\right)=0 \\
& \frac{\partial \mathrm{n}_{\mathrm{i}}}{\partial \mathrm{t}}+\frac{\partial}{\partial x}\left(\mathrm{n}_{\mathrm{i}} \mathrm{v}_{\mathrm{i}}\right)=0 \\
& \mathrm{n}_{\mathrm{o}} \frac{\partial \mathrm{v}_{\mathrm{e}}}{\partial \mathrm{t}}+\mathrm{n}_{\mathrm{e}} \mathrm{v}_{\mathrm{e}} \frac{\partial \mathrm{v}_{\mathrm{e}}}{\partial x}+\frac{\mathrm{kT}_{\mathrm{e}}}{\mathrm{m}_{\mathrm{e}}} \frac{\partial \mathrm{n}_{\mathrm{e}}}{\partial x}+\frac{\mathrm{eE \textrm {n } _ { \mathrm { e } }}}{\mathrm{m}_{\mathrm{e}}}=0 \\
& \mathrm{n}_{\mathrm{i}} \frac{\partial \mathrm{v}_{\mathrm{i}}}{\partial \mathrm{t}}+\mathrm{n}_{\mathrm{i}} \mathrm{v}_{\mathrm{i}} \frac{\partial \mathrm{v}_{\mathrm{i}}}{\partial x}+\frac{\mathrm{kT}_{\mathrm{i}}}{\mathrm{m}_{\mathrm{i}}} \frac{\partial \mathrm{n}_{\mathrm{i}}}{\partial x}-\frac{\mathrm{e} \mathrm{E}_{\mathrm{i}}}{\mathrm{m}_{\mathrm{i}}}=0 \\
& J=J_{\mathrm{e}}+J_{\mathrm{i}}=\mathrm{n}_{\mathrm{e}} \mathrm{v}_{\mathrm{e}}+\mathrm{n}_{\mathrm{i}} \mathrm{v}_{\mathrm{i}} .
\end{aligned}
$$

where the subscripts e and i refer to the electron and ion, respectively, $\mathrm{n}$ the density, $\mathrm{v}$ the velocity, T the temperature, $E$ the electric field, J the current density, $\epsilon$ the charge of an electron, $m$ the mass of an electron and $k$ the Eoltzmann constant. In these equations, c.g.s. electrostatic units are used.

Eqs. (1) and (2) represent the continuity equations for the electron and ion, respectively, and eqs.(3) and (4) the monentum transfer equations for the electron and ion, respectively. Eq. (5) is the expression for the conduction current density.

We apply to a neutral synthesized plasma a small, periodic oscillations of frequency $\boldsymbol{\omega}$, so that the 
Okuda. Yamamo to

variables can be written in the forms

$$
\begin{aligned}
& \mathrm{n}_{\mathrm{e}}=\mathrm{n}_{\mathrm{o}}+\Delta \mathrm{n}_{\mathrm{e}} \mathrm{e}^{i \omega \mathrm{t}} \\
& \mathrm{n}_{\mathrm{i}}=\mathrm{n}_{\mathrm{o}}+\Delta \mathrm{n}_{i} \mathrm{e}^{i \omega \mathrm{t}} \\
& \mathrm{v}_{\mathrm{e}}=\mathrm{v}_{\mathrm{e}_{\mathrm{o}}}+\Delta \mathrm{v}_{\mathrm{e}} \mathrm{e}^{i \omega \mathrm{t}} \\
& \mathrm{v}_{\mathrm{i}}=\mathrm{v}_{\mathrm{i}}+\Delta \mathrm{v}_{\mathrm{i}} \mathrm{e}^{i \omega \mathrm{t}} \\
& \mathrm{E}=\Delta \mathrm{E} \mathrm{e}^{i \omega \mathrm{t}} \\
& \mathrm{J}=\mathrm{J}_{\mathrm{o}}+\Delta \mathrm{J}^{i \omega \mathrm{t}}=\left(J_{\mathrm{eo}}+\mathrm{J}_{\mathrm{i}}\right)+\left(\Delta \mathrm{J}_{\mathrm{e}}+\Delta \mathrm{J}_{\mathrm{i}}\right) \mathrm{e}^{i \omega \mathrm{t}}
\end{aligned}
$$

Substituting eq.(6) into eqs.(1) through (5) and retaining terms of only first order in the small quantities, we obtain

$$
\begin{aligned}
& i \omega \Delta \mathrm{n}_{\mathrm{e}}+\frac{\partial}{\partial x}\left(\frac{\Delta \mathrm{J}_{\mathrm{e}}}{\mathrm{e}}\right)=0 \\
& i \omega \Delta_{\mathrm{i}}+\frac{\partial}{\partial x}\left(\frac{\Delta \mathrm{J}_{\mathrm{i}}}{\mathrm{e}}\right)=0 \\
& i \omega \mathrm{n}_{\mathrm{o}} \Delta \mathrm{v}_{\mathrm{e}}+\mathrm{n}_{0} \mathrm{v}_{\mathrm{e}} \frac{\partial \Delta \mathrm{v}_{\mathrm{e}}}{\partial x}+\frac{\mathrm{kT}_{\mathrm{e}}}{\mathrm{m}_{\mathrm{e}}} \frac{\partial \Delta \mathrm{v}_{\mathrm{e}}}{\partial x}+\frac{\mathrm{kT} \mathrm{e}}{\mathrm{m}_{\mathrm{e}}} \frac{\partial \Delta \mathrm{n}_{\mathrm{e}}}{\partial x}+\frac{\mathrm{n}_{\mathrm{o}} \mathrm{e} \Delta \mathrm{E}}{\mathrm{m}_{\mathrm{e}}}=0 \\
& i \omega \mathrm{n}_{\mathrm{o}} \Delta \mathrm{v}_{\mathrm{i}}+\mathrm{n}_{\mathrm{o}} \mathrm{v}_{\mathrm{i}} \frac{\partial \Delta \mathrm{v}_{\mathrm{i}}}{\partial x}+\frac{\mathrm{kT}_{\mathrm{i}}}{\mathrm{m}_{i}} \frac{\partial \Delta \mathrm{n}_{\mathrm{i}}}{\partial x}-\frac{\mathrm{n}_{\mathrm{o}} \mathrm{e} \Delta \mathrm{E}}{\mathrm{m}_{\mathrm{i}}}=0 \\
& \frac{\Delta \mathrm{J}_{\mathrm{e}}}{\mathrm{e}}=\mathrm{n}_{0} \Delta \mathrm{v}_{\mathrm{e}}+\mathrm{v}_{\mathrm{e}} \Delta \mathrm{n}_{\mathrm{e}} \\
& \frac{\Delta \mathrm{J}_{\mathrm{i}}}{\mathrm{e}}=\mathrm{n}_{\mathrm{o}} \Delta \mathrm{v}_{\mathrm{i}}+\mathrm{v}_{\mathrm{i}_{0} \Delta \mathrm{n}_{\mathrm{i}}}
\end{aligned}
$$


A Synthesized Plasma

From eqs. (11) and (12) together with eqs. (7) and (8), we have

$$
\begin{aligned}
& \Delta \mathrm{v}_{\mathrm{e}}=\frac{\Delta \mathrm{J}_{\mathrm{e}}}{\mathrm{n}_{0} \mathrm{e}}+\frac{\mathrm{v}_{\mathrm{e}_{\mathrm{o}}}}{\mathrm{n}_{\mathrm{o}} \mathrm{e}}\left(\frac{1}{i \omega} \frac{\partial \Delta \mathrm{J}_{\mathrm{e}}}{\partial x}\right) \\
& \Delta \mathrm{v}_{\mathrm{i}}=\frac{\Delta \mathrm{J}_{\mathrm{i}}}{\mathrm{n}_{0} \mathrm{e}}+\frac{\mathrm{v}_{\mathrm{i}}{ }^{\circ}}{\mathrm{n}_{\mathrm{o}} \mathrm{e}}\left(\frac{1}{i \omega} \frac{\partial \Delta \mathrm{J}_{\mathrm{i}}}{\partial x}\right)
\end{aligned}
$$

Eqs. (9) and (10) are then rewritten by

$$
\begin{aligned}
& \frac{1}{i \omega_{\mathrm{e}}}\left(\mathrm{v}_{\mathrm{e}_{\mathrm{o}}}^{2}-\frac{\mathrm{kT}_{\mathrm{e}}}{\mathrm{m}_{\mathrm{e}}}\right) \frac{\partial^{2} \Delta \mathrm{J}_{\mathrm{e}}}{\partial x^{2}}+\frac{2 \mathrm{v}_{\mathrm{e}}}{\mathrm{e}} \frac{\partial \Delta \mathrm{J}_{\mathrm{e}}}{\partial x}+\frac{i \omega}{\mathrm{e}} \Delta \mathrm{J}_{\mathrm{e}}=-\frac{\mathrm{en}_{\mathrm{o}}}{\mathrm{m}_{\mathrm{e}}} \Delta \mathrm{E} \\
& \frac{1}{i \omega_{\mathrm{e}}}\left(\mathrm{v}_{\mathrm{i}_{0}}^{2}-\frac{\mathrm{kT}_{\mathrm{i}}}{\mathrm{m}_{\mathrm{i}}}\right) \frac{\partial^{2} \Delta \mathrm{J}_{\mathrm{i}}}{\partial x^{2}}+\frac{2 \mathrm{v}_{\mathrm{io}}}{\mathrm{e}} \frac{\partial \Delta \mathrm{J}_{\mathrm{i}}}{\partial x}+\frac{i \omega}{\mathrm{e}} \Delta \mathrm{J}_{\mathrm{i}}=\frac{\mathrm{en}_{\mathrm{o}}}{\mathrm{m}_{\mathrm{i}}} \Delta \mathrm{E}
\end{aligned}
$$

The above equations turn out to be the ordinary differential equations, if the consideration is taken that the quantities are functions only of the space coordinates. Therefore, the solutions of the above equations are straightforward. The solution of eq. (15) for three cases, i.e., $\mathrm{v}_{\mathrm{e}_{\mathrm{o}}}^{2} \gg \mathrm{kT}_{\mathrm{e}} / \mathrm{m}_{\mathrm{e}}$, and $\mathrm{v}_{\mathrm{e}_{\mathrm{o}}}^{2} \ll$

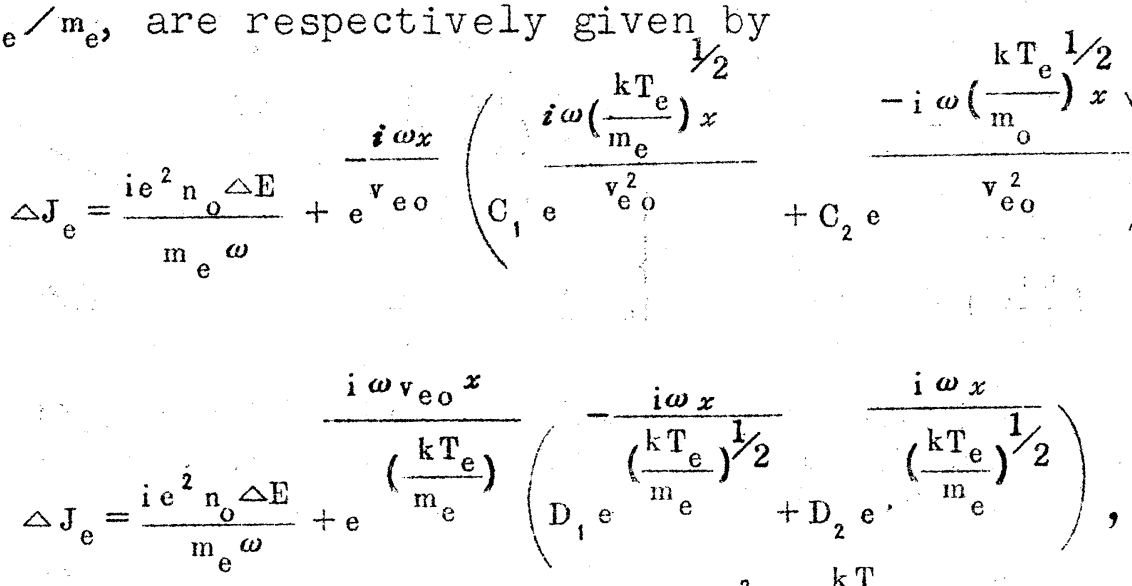

$$
\begin{aligned}
& v_{e_{o}}{ }^{2} \ll \frac{k_{\mathrm{T}}}{\mathrm{m}_{\mathrm{e}}}
\end{aligned}
$$


Okuda. Yamamo to

Next step is to determine the constants included in the above equations. This is done by use of the following boundary conditions :

$$
\Delta \mathrm{J}(x=0)=0, \quad \Delta \mathrm{J}(x=\mathrm{d})=0
$$

As the smallness of $\triangle \mathrm{Ji}$ compard with $\triangle \mathrm{Je}$ allows us to approximate

$$
\Delta \mathrm{I} \cong \Delta \mathrm{J}_{\mathrm{e}}
$$

then eq. (20) is written by

$$
\Delta \mathrm{J}_{\mathrm{e}}(x=0)=0, \quad \Delta \mathrm{J}_{\mathrm{e}}(x=\mathrm{d})=0
$$

With this boundary concition, we can find the constants $C_{1}, O_{2}, I_{1}$ and $D_{2}$. Finally, the expressions for $\Delta_{e}$ are respectively given by

$$
\begin{aligned}
& \Delta J_{e}=\frac{\mathrm{i} \mathrm{e}^{2} n_{0} \Delta E}{m_{\mathrm{e}} \omega}\left(1-\mathrm{e}^{-\frac{\mathrm{i} \omega_{x}}{\mathrm{v}_{\mathrm{e}}}}\right), \quad v_{\mathrm{eo}}^{2} \gg \frac{\mathrm{kT}_{\mathrm{e}}}{\mathrm{m}_{\mathrm{e}}} \\
& \Delta \mathrm{J}_{\mathrm{e}}=\frac{\mathrm{ie}^{2} \mathrm{n}_{0} \Delta \mathrm{E}}{\mathrm{m}_{\mathrm{e}} \omega}\left\{1-\mathrm{e}^{-\frac{\mathrm{i} \omega_{x}}{\left(\frac{\mathrm{kT}}{\mathrm{m}_{\mathrm{e}}}\right)^{1 / 2}}-\frac{\mathrm{e}^{-\left(\frac{\mathrm{kT}}{\mathrm{m}_{\mathrm{e}}}\right)^{1 / 2}-1}}{\frac{\mathrm{i} \omega_{\mathrm{d}}}{\mathrm{e}^{-\left(\frac{\mathrm{kT}}{\mathrm{m}_{\mathrm{e}}}\right)^{1 / 2}}+\mathrm{e}\left(\frac{\mathrm{kT} \mathrm{e}}{\mathrm{m}_{\mathrm{e}}}\right)^{1 / 2}}}}\right. \\
& \left.\left(\frac{i \omega_{x}}{\left(\frac{\mathrm{kT} \mathrm{T}_{\mathrm{e}}}{\mathrm{m}_{\mathrm{e}}}\right)^{1 / 2}}-\frac{i \omega x}{\left(\frac{\mathrm{kT} \mathrm{e}}{\mathrm{m}_{\mathrm{e}}}\right)^{\frac{1}{2}}}\right)\right\}, \mathrm{v}_{\mathrm{e} o}^{2} \ll \frac{\mathrm{kT} \mathrm{T}}{\mathrm{m}_{\mathrm{e}}}
\end{aligned}
$$

Now, the impedance per unit length and per unit cross section is defined as the ratio of the a.c. electric field to the a.c.current

$$
\mathrm{Z}=\frac{\Delta \mathrm{E}}{\Delta \mathrm{I}}
$$




\section{A Synthesized Plasma}

The current appeared in the above equation is the sum of the conduction and capacitive currents and is described as

$$
\Delta \mathrm{I}=\Delta \mathrm{J}+\frac{\mathrm{i} \omega}{4 \pi} \quad \Delta \mathrm{E} \cong \Delta \mathrm{J}_{\mathrm{e}}+\frac{\mathrm{i} \omega}{4 \pi} \Delta \mathrm{E}
$$

The impedances per unit lenght and per unit cross section for three cases are thus obtained making use of eqs.(22) to (24) as

$$
\mathrm{Z}=-\frac{\mathrm{i} 4 \pi}{\omega} \frac{1}{\frac{\omega_{\mathrm{p}}^{2}}{\omega^{2}}\left(1-\mathrm{e}^{-\frac{\mathrm{i} \omega x}{\mathrm{e}_{\mathrm{o}}}}\right)+1}, \quad \mathrm{v}_{\mathrm{ec}_{\mathrm{C}}}^{2} \gg \frac{k \mathrm{~T}_{\mathrm{e}}}{\mathrm{m}_{\mathrm{e}}}
$$

$$
\mathrm{Z}=-i \frac{4 \pi}{\omega}
$$

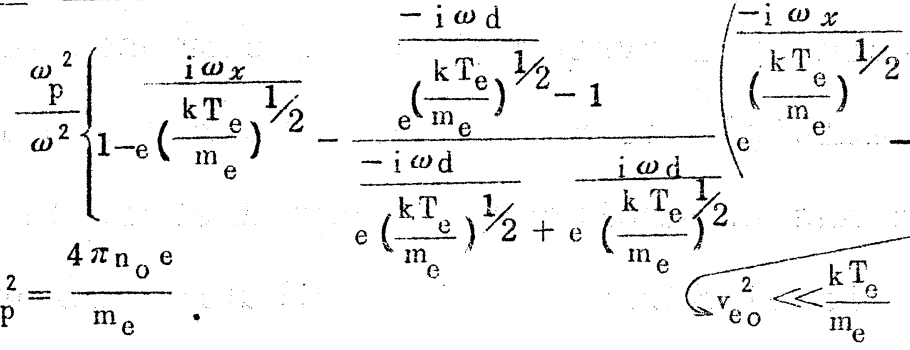

$$
\begin{aligned}
& 1
\end{aligned}
$$

where $\omega_{\mathrm{p}}^{2}=\frac{4 \pi_{\mathrm{n}_{\mathrm{o}}} \mathrm{e}}{\mathrm{m}_{\mathrm{e}}}$.

As seen from these results, the current density or the impedance is periodic in space when the conditions $\mathrm{v}_{\mathrm{e}}^{2} \gg \mathrm{kT}_{\mathrm{e}} / \mathrm{m}_{\mathrm{e}}$ and $\mathrm{v}_{\mathrm{e}}^{2} \ll \mathrm{kT}_{\mathrm{e}} / \mathrm{m}_{\mathrm{e}}$ are satisfied.

Also, we may have a hope that the observation of the periodicity leads to the estimation of the electron temperature. The measurement of the periodicity may be made by a movable search coil.

However, it is emphasized that in the above analysis 
Okuda. Yamamo to

no excitation of wave was considered.

IV. Summary

We proposed a new means of synthesizing plasma and showed a result concerning the response of a neutral synthesizing plasma to an alternation electric field as an example of the properties.

We are now constructing an experimental device to investigate the subjects describec in the preceding paragragh. In the second'stage, the present system consisting of an electron beam and an ion beam will be replaced by a system which is composed of combination of multiple beams of the electron and ion, each of which has an arbitrary energy distribution. A unidirectional Maxwellian distribution is attainable with using a one-dimensional device similar to that described in this paper, but an isotropic Maxwellian distribution may be obtained by an spherical device, in which the beams are radially injected toward the eenter. 


\section{A Synthesized Plasina}

References

(1) R.C.KnechtIi and J.Y.Wada, Phys. Rev. Letters, 6, 215, 1961.

(2) G.S.Kino, Radiation and Waves in Plasma, edited by M.Mitchner, Stanford University Press., 1961.

(3) M.L.Bromberg and B.A.Free, IEEE Trans. Aerospace, 2, 509, 1964 .

(4) Okuda and K. Yamamoto, KAKUYUGO KENKYU, 11, 146, 1963. 